\title{
Germplasm and conservation of rare and endangered tree species endemic to east China
}

\author{
Liu Jun and Jiang Jingmin $ه$
}

\begin{abstract}
There are plenty of native tree species in east China, including 16 rare and endangered tree species belonging to 11 genera in 10 families. Because of narrow distribution area, weak qualitative competitiveness and reduced natural regeneration, the number of these tree species are decreasing substantially. Thus, it is necessary to protect endangered species endemic to the region. In this paper the basic data on germplasm, geographical distribution, biological characters, endangered status and current conservation strategies of rare and endangered species endemic to east China are presented. The gap areas were identified and accordingly implications were made on the future work on the native rare and endangered tree species in east China should focus on the basic research of conservation biology, establishment of the information system, solution of problems in reproductive biology and more emphasis on the key regions for protecting biodiversity.
\end{abstract}

Keywords: east China; rare and endangered; germplasm; conservation

\section{Introduction}

East China is a geographical region having an area of 65.86 square kilometres that covers the south-eastern coastal zone of China, including provinces of Zhejiang, Jiangsu, Shandong, Fujiang, Jiangxi, Anhui and Shanghai (Wu \& Wang, 1983; Liu et al., 1995). Most of this region is

Received: 06 May 2014 / Accepted revised version: 18 August 2014 / Published online: 01 October 2014

(C) Horizon e-Publishing Group

CITATION

Jun, L., \& Jingmin, J. (2014). Germplasm and conservation of rare and endangered tree species endemic to east China. Plant Science Today, 1(4), 183-187. http://dx.doi.org/10.14719/pst.2014.1.4.46

\section{AUTHOR'S AFFILIATION}

Research Institute of Subtropical Forestry, Chinese Academy of Forestry, Fuyang, Zhejiang 311400, PR China

CORRESPONDENCE

\Dr. Jiang Jingmin, Tel.: +86 5716331 0915; Fax: +86 5716331 0915; Email: jiang_jingmin@163.com part of northern and mid-subtropical monsoon region with superior nature conditions, annual rainfall about $1100 \mathrm{~mm}$, flush precipitation and moderate climate. Hence east China is one of the key biodiversity regions in the world (Gao et al., 2002; Ma, Tian, \& Hu, 2010). With the global industrial expansion and the increase in urban population, the biodiversity of the world is decreasing rapidly and east China region is not an exception to this fact where ecological system is severely damaged and a large number of plant species have become extinct or endangered (Xue et al., 1991; Hao et al., 2000; Hu, Ding, \& Chen, 2002; Zheng \& Jin, 2008).

Due to special geographical environment and climatic conditions, there are so many rare and endangered tree species endemic to east China, such as Abies beshanzuensis, Sinocalycanthus chinensis, Ostrya rehderiana and Magnolia cylindrica. Because of narrow distribution area, weak qualitative competitiveness and slowness in natural regeneration, the number of these tree species are reduced substantially. Thus, it is necessary to take immediate measures to protect endangered species endemic to the region in the background of global climate change. In this paper the basic data on germplasm, geographical distribution, biological characters, endangered status and current conservation strategies of rare and endangered species endemic to east China were reviewed.

Wild germplasm of rare and endangered tree species endemic to east China

There are 16 rare and endangered tree species endemic to east China belonging to 11 genera in 10 families (Table 1). Two tree species of them are national first class protected wild tree species, including Abies beshanzuensis and Carpinus putoensis (Fu, 1992; Wang, An, \& Leng, 2004). Number of national secondary and third class protected endangered tree species is seven and five in east China, accounting for $43.8 \%$ and $31.3 \%$ respectively. The last two tree species, including Carpinus tientaiensis and Tilia miqueliana, are not listed in the China red list of threatened plants. The two species are worth to study for their endangered status (Tang \& Tang, 2007; Tang, Peng, \& 
Table 1. Number and distribution of rare and endangered tree species endemic to east China

\begin{tabular}{|c|c|c|c|c|}
\hline Species & $\begin{array}{l}\text { Protection } \\
\text { grade }\end{array}$ & $\begin{array}{l}\text { Wild individual } \\
\text { number }\end{array}$ & $\begin{array}{l}\text { Distribution } \\
\text { area } / \mathrm{hm}^{2}\end{array}$ & Distribution and Habits \\
\hline Abies beshanzuensis & 1 & 4 & 0.1 & Zhejiang province, Alt. (altitude) $1700 \mathrm{~m}$ in beach forest \\
\hline Carpinus putoensis & 1 & 1 & 0.05 & Zhejiang province, Alt.240m, in zhoushan island \\
\hline Torreya jackii & 2 & 7000 & 56 & $\begin{array}{l}\text { Zhejiang and Fujian province, Alt. } 200-800 \mathrm{~m} \text { in steep } \\
\text { shady slope or evergreen forest along both sides of } \\
\text { valley }\end{array}$ \\
\hline $\begin{array}{l}\text { Sinojackia } \\
\quad \text { xylocarpa }\end{array}$ & 2 & 0 & 0 & Jiangsu province, Alt.300-800m in forest edge \\
\hline Ostrya rehderiana & 2 & 5 & 0.4 & Zhejiang province, Alt.160m along both sides of valley \\
\hline Neolitsea sericea & 2 & 130 & 10 & $\begin{array}{l}\text { Zhejiang, Shanghai and Jiangsu province, Alt.150-350m } \\
\text { in evergreen forest of gully }\end{array}$ \\
\hline $\begin{array}{l}\text { Sinocalycanthus } \\
\text { chinensis }\end{array}$ & 2 & 60000 & 500 & $\begin{array}{l}\text { Zhejiang province, Alt. } 600-1000 \mathrm{~m} \text { understory along } \\
\text { both sides of valley }\end{array}$ \\
\hline Ulmus elongata & 2 & 300 & 20 & $\begin{array}{l}\text { Zhejiang and Fujian province, Alt.400-800m in open } \\
\text { forest }\end{array}$ \\
\hline $\begin{array}{l}\text { Phoebe } \\
\text { chekiangensis }\end{array}$ & 2 & 3000 & 200 & $\begin{array}{l}\text { Zhejiang, Jiangxi and Fujian province, Alt.1500-1000m } \\
\text { in open forest of gully }\end{array}$ \\
\hline Magnolia cylindrica & 3 & 8600 & 600 & $\begin{array}{l}\text { Zhejiang, Anhui, Jiangxi and Fujian province, } \\
\text { Alt.600-1700m in open forest of gully }\end{array}$ \\
\hline Magnolia amoena & 3 & 12000 & 900 & $\begin{array}{l}\text { Zhejiang, Anhui, Jiangxi and Jiangsu province, Alt.200- } \\
\text { 1000m in evergreen or mixed forest }\end{array}$ \\
\hline Ulmus gaussenii & 3 & 30 & 10 & Anhui province, Alt. $60-100 \mathrm{~m}$ along both sides of brook \\
\hline Magnolia zenii & 3 & 18 & 5 & $\begin{array}{l}\text { Jiangsu province, Alt.180-230m in north slope of } \\
\text { Baohua mountain }\end{array}$ \\
\hline Acer yangjuechi & 3 & 1 & 1 & $\begin{array}{l}\text { Zhejiang province, Alt. } 240-500 \mathrm{~m} \text {, in mixed forest of } \\
\text { Tianmu Mountain }\end{array}$ \\
\hline $\begin{array}{l}\text { Carpinus } \\
\quad \text { tientaiensis }\end{array}$ & None & 21 & 0.3 & $\begin{array}{l}\text { Zhejiang province, Alt. } 800-1000 \mathrm{~m} \text {, in forest of Tiantai } \\
\text { Mountain }\end{array}$ \\
\hline Tilia miqueliana & None & 500 & 10 & $\begin{array}{l}\text { Jiangsu, Zhejiang and Anhui province, Alt.180-300m in } \\
\text { broadleaf forests }\end{array}$ \\
\hline
\end{tabular}

Tang, 2008; Chen, Ke, Yang, \& Yan, 2010), hence they are listed in this article.

Zhejiang province is located in the Mid-East of east China, so biodiversity in this zone is very rich ( $\mathrm{Hu}$ et al., 2002; Wang \& Zhu, 2004). There are 13 rare and endangered tree species endemic to east China, which account for $81.3 \%$ of the total number of species. Therefore, Zhejiang province is very important in protection of biodiversity of east China. There are 6 endangered tree species endemic to Zhejiang province, such as Carpinus tientaiensis, Abies beshanzuensis, Carpinus putoensis, Ostrya rehderiana, Sinocalycanthus chinensis and Acer yangjuechi. So there is serious need for conservation of rare and endangered tree species in Zhejiang province. Five endangered tree species endemic to east China have been found in Jiangsu province, two of them are endemic to Jiangsu province, including Magnolia zenii (Wang, Ding, Zhao, Cheng, \& Shen, 2008; Sun, Dou, Liu, \& Liu, 2008) and Sinojackia xylocarpa (Chen, 1957; Jia \& Shen, 2007). Neolitsea sericea is the only one endangered tree species in Shanghai.
Great differences in the number of wild individuals among the tree species were observed. There were only less than 10 individuals reported for Abies beshanzuensis (Ai, Qiu, Yu, Chen, \& Ding, 2005), Carpinus putoensis (Li et al., 2010), Sinojackia xylocarpa, Ostrya rehderiana (Wang et al., 2008) and Acer yangjuechi (Lou, Zhao, Yang, \& Pang, 2004). Especially for Sinojackia xylocarpa, no natural distribution was found in Jiangsu province recently (Jia \& Shen, 2007).

\section{Reasons why the tree species became endangered}

Reasons for the tree species endemic to east China becoming endangered are various, such as narrow natural distribution area, low level of genetic diversity, habitat changes, poor natural regeneration and weak population competitiveness (Oldfield, Lusty, \& MacKinven, 1998). Some factors are extrinsic to the life history of the species in their distribution area and habitats, while others are intrinsic and reflect fundamental biological attributes that may constrain distribution and abundance (Pavlik, 1994; Hao \& Liu, 2007). When efforts are made on their 
conservation and recovery, it is important to assess main factors that result in the decline of their populations.

The low level of genetic diversity is the most important reason for endangering the tree species endemic to east China. Genetic diversity of Abies beshanzuensis and Carpinus putoensis is very low due to relatively less number of wild individuals in natural population (Ai et al., 2005; He, 2009; Zhang, Wang, \& Li, 2011). Neolitsea sericea also showed a low level of genetic diversity. The isolated distribution pattern of $N$. sericea among several islands is relatively recent ( $<9000$ years). Shared common ancestry and similar selective regimes before the archipelago was separated from the mainland may account for the low level of genetic diversity seen in N. sericea (Schaal, Hayworth, Olsen, Rauscher, \& Smith, 1998; Wang et al., 2005). Although the wild individual number of Sinocalycanthus chinensis and Torreya jackii is more than thousands, the genetic variation is low for these two endangered tree species (Li \& Jin, 2006; Li \& Jin, 2007).

Plant species with restricted geographical distributions tend to be more threatened than the widespread plants (Gitzendanner \& Soltis, 2000; Nybom \& Bartish, 2000), so restricted geographical distribution is another reason for endangered tree species of east China. Low genetic diversity at population level in T. jackii could be attributed to restrictive geographical distribution and isolated populations. Two of the endangered tree species, such as Ostrya rehderiana and Acer yangjuechi, are only distributed in Tianmu Mountain. One population was found for these two species in this zone, and the distribution area is 0.4 and $1 \mathrm{hm}^{2}$, respectively ( $\mathrm{Hu}$ et al., 2002), therefore, population development was restricted by narrow geographical distribution.

Natural regeneration of plants is a complicated ecological process, which plays an important role in the multiplication, spread and continuation of plant populations and the stabilization and succession of plant communities (Li, Peng, \& Dang, 2007). Therefore the poor natural regeneration ability will be one of reasons for the rare tree species of east China that became endangered as reported for many endangered tree species such as Tilia miqueliana (Tang et al., 2008), Ulmus elongate (Jiang, 2003) and Ostrya rehderiana (Guan \& Tao, 1988). The regeneration ability is related to seed vigour, seed dormancy, pollen viability and environment. The seed germination rate is very low based on indoor germination experiment (Zhang et al., 1988). It is highly significant to note that no wild progeny seedlings were found under the trees in their natural habitats.

Population competitiveness can reflect the population dynamics and trends (Wang, An, \& Zhu, 1998). If competitiveness is very strong for a tree species, it can be denoted as a dominant population. A dominant population will be turned into an endangered population with competitiveness decreasing ( $\mathrm{Li}, \mathrm{Su}, \&$ Xiang, 2002). The age structure of the populations were declining due to lack of seedlings for Magnolia cylindrica (Liu, Zhang, \& Liu, 2010), Tilia miqueliana (Tang et al., 2008) and Abies beshanzuensis (Hu, Shao, Qian, \& Zhou, 2004).

Population declines are often attributed to habitat changes (Evans, 2004). The endangered tree species exhibited habitat specificity as reported for Abies beshanzuensis (Wu, Zhou, \& Chen, 2009) and Ostrya rehderiana (Guan \& Tao, 1988). These two tree species may be extinct owing to habitat changes. According to field observations, populations of $T$. jackii are dramatically shrinking in China due to heavy deforestation and extensive habitat loss in the past decades (Gao, 1996). Due to gradual fragmentation of the habitat, T. jackii is gradually limited to small isolated areas, and eventually fragmented into island-like small populations (Li \& JIn, 2007).

\section{Conservation status of these rare and endangered tree species}

The conservation efforts must be given high priority for the endangered tree species endemic to east China. With the development of economy in east China, the governments have been realizing the importance of protecting biodiversity. Fourteen of these endangered tree species have been listed in China red list of threatened plants (Fu, 1992). The first law for protecting wild plants was published by the state council officially in 1996 (Wu, Huang, \& Ding, 2004). Studies on conservation biology and genetics were carried out by the main research centres in east China. The research contents cover genetic diversity assessment, population structure, flowering and fruit characteristics, artificial propagation, conservation strategies and so on.

It is necessary to have some background knowledge of the population genetic diversity when one want to know the threatened level of a rare species. Half of the endangered tree species endemic to east China were undergone genetic diversity assessment. The genetic diversity of $T$. jackii at species level was relatively high, whereas the genetic diversity at the population level was relatively low (Li et al., 2007), and the same results were found for S. chinensis (Li \& Jin, 2007). Genetic diversity and genetic differentiation were examined in six populations of the insular endangered plant $N$. sericea in Zhoushan archipelago using random amplified polymorphic DNA (RAPD) markers. The results indicated that $N$. sericea had a lower level of genetic diversity than other insular plants (Wang et al., 2004). Population pattern and diversity of the communities of many endangered tree species endemic to east China have also been studied. For example, the structure of diameter class of $T$. miqueliana population 
appeared as on inverted pyramid and the population was declining with the survival curve of Deevey III and was unstable at seedling stage with a high death rate of the saplings. The regeneration modes of the population were seed germination and vegetative propagation, and the later played an important role in keeping population size (Tang \& Tang, 2007).

Until 2010, 47 national nature reserves have been constructed in east China. All the endangered tree species endemic to east China have been protected in these natural reserves. Because of the narrow habitat specificity of the endangered tree species such as Abies beshanzuensis and Ostrya rehderiana, in situ conservation should be considered as the most important management activity for these species, and natural regeneration should be promoted (Jin, Yu, \& Ding, 2002; Ma et al., 2010). Ex situ conservation is very useful for the endangered tree species which are easy to propagate, such as $S$. xylocarpa and $P$. chekiangensis.

\section{Conclusion and future prospects}

The germplasm of endangered tree species endemic to east China is an important part of the biodiversity of the region. Protection of these threatened bioresources are given high priority and worth studying due to their ancient origin, endemism, population bottlenecks and for developing suitable conservation approaches.

The basic research work on conservation biology including analysis of distribution range and pattern, size and structure of populations, characteristics of habitats, reasons for species becoming endangered and so on have to be carried out. An information system on endangered tree species endemic to east China needs to be established based on these data which would assist to develop conservation strategies. Studies on reproductive biology are important for tree species that are difficult to propagate, such as Ostrya rehderiana, Carpinus tientaiensis and Tilia miqueliana. No seedlings of Ostrya rehderiana were found in natural forest or on market. Hence one must study seed dormancy and germination process, and advanced seedling technologies have to be introduced to solve the problem. In vitro techniques have been found beneficial for ensuring the conservation of threatened plants in recent years and this trend will likely to be continued.

There are 13 endangered tree species endemic to east China in Zhejiang province. Conservation of endangered tree species in Zhejiang province is more important than that in other provinces in east China. Based on distribution characters of endangered tree species endemic to east China, Zhoushan archipelago, Wuyi mountain, Xitianmu mountain, Baohua mountain and Dabie mountain are the key regions for protecting biodiversity. Conservation sites have to be established at regions where higher numbers of tree species are on the edge of extinction.

\section{Acknowledgments}

We want to express our sincere thanks to Prof. Zong-xiu Sun and Prof. Shao-qing Hu. This work was supported by National Natural Science Foundation Project (Grant number: 31100487).

\section{References}

Ai, J. G., Qiu, Y. X., Yu, J. H., Chen, X. R., \& Ding, B. Y. (2005). Optimization of inter simple sequence repeats (ISSR) analysis as applied to preliminary study of genetic variation in Abies beshanzuensis M. H. Wu. Journal of Zhejiang University (Agriculture and life science), 31 (3), 277-282.

Chen, M. S., Ke, S. S., Yang, Y. Y., \& Yan, Q. Q. (2010). Anatomical Study on Vegetative Organs of Carpinus tientaiensis. Journal of Zhejiang Forestry Science and Technology, 30 (5),14-19.

Chen, R. (1957). Chinese dendrology classification: 1011-1012. Beijing: Science Publishing House.

Evans, K. L. (2004). The potential for interactions between predation and habitat change to cause population declines of farmland birds. Ibis, 146, 1-13. http://dx.doi.org/10.1111/j.1474-919X.2004.00231.x

Fu, L. G. (1992). China plant red data book- threatened plants (Vol.1). Beijing: Science Publishing House.

Gao, X. M., Wang, C., Hou, S. Q., \& Ma, K. P. (2002). Study progress on conservation ecology in China - The $5^{\text {th }}$ National Symposium of Protection Conservation. Beijing: Science Publishing House, 37-45.

Gao, Z. W. (1996). Study on the biological character and conservation of endemic species Torreya jackii. Bodiversity Science, 5 (3), 206-209.

Gitzendanner, M. A, \& Soltis, P. S. (2000). Patterns of genetic variation in rare and widespread plant congeners. American Journal of Botany, 87 (6), 783-792. http://dx.doi.org/10.2307/2656886 PMid:10860909

Guan, K. L., \& Tao, Y. Z. (1988). Current situation and propagation of rare tree species - Ostrya rederiana. Journal of Zhejiang Forestry College, 5 (1), 90-92.

Hao, C. Y., \& Liu, P. (2007). Endangering causes of an endemic plant Heptacodium miconioides in East China. Scientia silvae sinicae, 43 (7), 86-92.

Hao, R. M., Huang, Z. Y., Liu, X. J., Wang, Z. L., Xu, H. Q., \& Yao, Z. G. (2000). Chinese Biodiversity, 8 (2), 153-162.

He, F. L. (2009). Price of prosperity: economic development and biological conservation in China. Journal of Applied Ecology, 46, 511-515 http://dx.doi.org/10.1111/j.1365-2664.2009.01641.x

Hu, B. Z., Shao, S. L., Qian, H., \& Zhou, Q. M. (2004). Study on aspect and structure properties of Abies beshanzuensis phyto-group. Journal of Zhejiang Forestry Science and Technology, 24 (3),12-16.

Hu, S. Q., Ding, B. Y., \& Chen Z. H. (2002). The critical regions for conservation of rare and endangered plant species diversity in Zhejiang province. Biodiversity science, 10 (1), 15-23.

Jia, S. G., \& Shen, Y. B. (2007). Research progress on Sinojackia xylocarpa Hu. Journal of Jiangsu Forestry Science and Technology, 34 (6), 41-45. 
Jiang, Y. S. (2003). The study on natural regeneration of Ulmus elongate. Journal of Fujian Forestry Science and Technology, 30(4),, 55-58.

Jin, S. H., Yu, J., \& Ding, B. Y. (2002). Current situation of distribution and donservation of national wild plants for protection in Zhejiang province. Journal of Zhejiang Forestry Science and Technology, 22(2), 48-53.

Li, J. M., \& Jin, Z. X. (2006). High genetic differentiation revealed by RAPD analysis of narrowly endemic Sinocalycanthus chinensis Cheng et S.Y. Chang, an endangered species of China. Biochemical Systematics and Ecology, 34(10), 725-735. http://dx.doi.org/10.1016/i.bse.2006.06.010

Li, J. M., \& Jin, Z. X. (2007). Genetic variation and differentiation in Torreya jackii Chun, an endangered plant endemic to China. Plant Science, 172, 1048-1053. http://dx.doi.org/10.1016/i.plantsci.2007.02.009

Li, X. K., Su, Z. M., \& Xiang W. S. (2002). Study on the structure and spatial pattern of the endangered plant population of Abies yuanbaoshanensis. Acta Ecologica Sinica, 22(12), 2246-2253.

Li, X. P., Yu, C. Y., Wu, Y. Y., Hong, Z. Y., Sun, J., Chen, Y. P., \& Chou, L. X. (2010). The biological reason for endangerment of Carpinus putoensis and measures for gene conservation. Scientia Silvae Sinicae, 46(7), 69-76.

Li, X. S., Peng, C. M., \& Dang, C. L. (2007). Research progress on natural regeneration of plants. Chinese Journal of Ecology, 26(12), 2081-2088.

Liu, C. S., Zhang, Y., \& Liu, P. (2010). Community structure and population characteristics of Magnolia cylindrical at Jiulongshan National Nature Reserve. Journal of Zhejiang Forestry Science and Technology, 30(1), 1-7.

Liu, F. X., Liu, S. H., Yang, Z. B., Hao, R. M., Yao, J., Huang, Z. Y., \& Li. N. (1995). A floristic study on the seed plants from the region of east China. Acta Botanica Yunnanica, 93-110

Lou, T., Zhao, M. S., Yang, S. Z., \& Pang, C. M. (2004). Resources of precious and ancient trees in Mount Tianmu. Journal of Zhejiang Forestry College, 21(3), 269-274.

Ma, Q. X., Tian, Q., \& Hu, Y. H. (2010). Rare and endangered plants and their protection in east China. Journal of Hubei University for Nationalities, 28(3), 310-313.

Nybom, H., \& Bartish, I. V. (2000). Effects of life history traits and sampling strategies on genetic diversity estimates obtained with RAPD markers in plants. Perspectives in Plant Ecology, Evolution and Systematics, 3, 93-114. http://dx.doi.org/10.1078/1433-8319-00006

Oldfield, S. F., Lusty, C., \& MacKinven, A. (1998). The world list of threatened trees. Cambridge: World Conservation Press.

Pavlik, B. M. (1994). Demographic monitoring and the recovery of endangered plants - Bowles, M, \& Whelan, C. In Restoration of endangered species. Cambridge: Cambridge University Press, 322- 350 http://dx.doi.org/10.1017/CB09780511623325.017

Schaal, B. A., Hayworth, D. A., Olsen, K. M., Rauscher, J. T., \& Smith, W. A. (1998). Phylogeographic studies in plants: problems and prospects. Molecular Ecology, 7, 465-474. http://dx.doi.org/10.1046/i.1365-294x.1998.00318.x

Sun, Q. M., Dou, J., Liu, X. J., \& Liu, X. W. (2008). Investigation on the Magnoliaceae plant resources in east China. Journal of Anhui Agricultural Science, 36(34), 14956-14957.

Tang, S. J., \& Tang, G. G. (2007). Analysis on structure of Tilia miqueliana population in Huangcangyu nature reserve of
Anhui province. Journal of Plant Resources and Environment, 16(3), 58-63.

Tang, S. J., Peng, Z., \& Tang, G. G. (2008). A community characteristics analysis on Tilia miqueliana in Baohua Mt. Journal of Yangzhou University (agricural and life science edition), 29(1), 90-94.

Wang, C. T., \& Zhu, S. C. (2004). Resources of rare plant in Zhejiang province and distribution in natural reserves. Chinese wild plant resources, 23(4), 26-28.

Wang, Z. F., An, S. Q., \& Zhu, X. L. (1998). Distribution pattern of tree populations in tropical forest and comparison of its study methods. Journal of Applied Ecology, 9(6), 575-580.

Wang, Z. L., Ding, L. X., Zhao, M. S., Cheng, X. Y., \& Shen, Q. (2008). Genetic diversity of Ostrya rehderiana revealed by RAPD markers. Journal of Zhejiang Forestry College, 25(3), 304-308.

Wang, Z. S., An, S. Q., \& Leng, X. (2004). Population genetic diversity of the insular plant Neolitsea sericea based on random amplified polymorphic DNA (RAPD). Acta Ecologica Sinica, 24(3), 414-422.

Wang, Z. S., An, S. Q., Liu, H., Leng, X., Xheng, J. W., \& Liu, Y. H. (2005). Genetic Structure of the Endangered Plant Neolitsea sericea (Lauraceae) from the Zhoushan Archipelago Using RAPD Markers. Annals of Botany, 95, 305-313. http://dx.doi.org/10.1093/aob/mci027 PMid:15546928

Wu, X. Q., Huang, B. L., \& Ding, Y. L. (2004). The advance on the study of protection of rare and endangered plants in China. Journal of Nanjing forestry university, 28(2), 72-76.

Wu, Y. G., Zhou, R. F., \& Chen, X. R. (2009). Comparison of the growth of Abies beshanzuensis under different cultivated environments. Forestry Science and Technology, 34(6), 8-10.

Wu, Z. Y., \& Wang, H. S. (1983). Chinese nature geography-plant geography. Beijing, science publishing house.

Xue, D. Y., Jiang, M. K., Li, Z. F., Huang, Z. Y., Zong, S. X., \& Yang, K. H. (1991). Study on the grading indexes for the rare and endangered plants in Jiangsu, Zhejiang and Anhui provinces. China Environmental Science, 11(3), 161-166.

Zhang, R. H., Gong, G. W., Shen, X. K., Zhou, D. M., Kang, Z. X., \& Yang, F. C. (1988). A study of pollen, seed and seedling of Ostrya rederiana. Journal of Zhejiang Forestry Science and Technology, 8(4), 7-11.

Zhang, X. H., Wang, Z. J., \& Li, X. P. (2011). RAPD analysis of genetic diversity of different progenies from endangered plant Carpinus putoensis. Journal of Shandong Forestry Science and Technology, 41(1), 1-5.

Zheng, Z. Z., \& Jin, X. F. (2008). Study on the Chinese endemic genera of seed plants distributed in the region of east China. Journal of Zhejiang University (Science edition), 35 (6), 668-673.

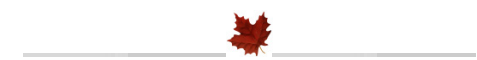

